\title{
Heterosis and inheritance of fertility-restorer genes in rice
}

\author{
Jakkrit Seesang, Prapa Sripichitt, Tanee Sreewongchai* \\ Department of Agronomy, Faculty of Agriculture, Kasetsart University, Bangkok 10900 Thailand \\ *Corresponding author, e-mail: agrtns@ku.ac.th
}

Received 26 Dec 2012

Accepted 4 Nov 2013

\begin{abstract}
Three-line hybrid rice technology can increase rice yield. This study aims to identify restorers and maintainers, to estimate heterosis of hybrid rice, and to identify fertility-restorer genes of $F_{2}$ populations. The analysis of 31 test crosses revealed 6 restorers and 9 maintainers based on pollen fertility. The estimation of heterosis to select superior genotypes was conducted on 12 hybrids resulting from crosses between 6 restorers and 2 male sterile lines. The results show that two hybrids had a high heterobeltiosis and standard heterosis, with yields of 7940 and $6810 \mathrm{~kg} / \mathrm{ha}$, respectively. The inheritance of fertility-restorer genes of $\mathrm{F}_{2}$ populations in crosses IR80151A/CH1 and IR80151A/CH4 was evaluated at heading to flowering stage based on pollen fertility and seed setting rate (SSR). The segregation ratio of pollen fertility was 15:1 (fertile: sterile), representing two nuclear independent dominant genes controlling the trait with sporophytic abortive fertility. The SSR, however, could not be used to study fertility-restorer genes, as it is influenced by physiological and environmental factors.
\end{abstract}

KEYWORDS: maintainer, restorer, pollen fertility

\section{INTRODUCTION}

The phenomenon of heterosis has been clearly established in rice and is evident in several agronomic traits already being marketed in China. The threeline hybrid rice research in Thailand started in 1980. The cytoplasmic male sterility (CMS) is maternally inherited and characterized by a failure to produce functional pollen, this phenomenon has been found in many species of plants and is conveniently used for hybrid plant production ${ }^{1}$. The CMS system in rice consists of three lines including male sterile, maintainer, and restorer lines, where the identification of maintainers and restorers of rice lines/cultivars is essential to improve the rice vigour. Ingale et $\mathrm{al}^{2}$ identified 40 effective restorers and 77 maintainers among 145 rice genotypes by test cross with male sterile lines. Thus the identification of rice germplasm was the first important role for three-line hybrid rice breeding program ${ }^{3-6}$. The estimation of heterosis is attributed to one or more morphological traits, of which hybrid rice varieties show 15-20\% higher yield potential than inbred varieties ${ }^{5}$. Besides, the estimation of yield and yield components heterosis has been extensively used to improve the breeding of hybrid rice ${ }^{7-10}$.

The fertility of CMS system can be restored by nuclear restorer genes ${ }^{1}$, that need to be identified before implementing the production of hybrid rice. Although a variation number of these genes have been proposed in various restorer lines, IR80151A is male sterile line of wild-abortive cytoplasmic male sterility system (WA-CMS) controlled by two independent dominant genes with sporophytic abortive fertility ${ }^{11}$. Others have reported that WA-CMS is controlled by monogenic ${ }^{12}$, digenic ${ }^{12-14}$, digenic interaction, and trigenic mechanisms ${ }^{15}$. In Thailand, the identification of maintainers and restorers has progressed relatively slow with the WA-CMS used by the source of international rice research institute. Consequently, the objectives of this study are to identify maintainers and restorers of Thai rice germplasm and to identify fertility-restorer genes, both of which play an important role in developing new male sterile and restorer lines to use for heterosis improvement of hybrid rice production.

\section{MATERIALS AND METHODS}

This study consists of three experiments. The first one was the identification of rice germplasm as maintainers and restorers. The $31 \mathrm{~F}_{1}$ test crosses were obtained from crosses between 2 male sterile lines as female parents and 17 rice germplasm as male parents. They were hybridized along with their respective parental lines and 5 check varieties were transplanted in an augmented randomized complete block design with 3 replicates at Kasetsart University, Bangkok, Thailand, during the 2010 wet season (about 16 plants per plot, spaced $25 \mathrm{~cm}$ apart). To identify maintainer and re- 
storer lines, pollen was stained with $2 \% \mathrm{IKI}_{2}$ solution of 4 middle plants of each plot. If the $F_{1}$ test cross population had fertile pollen, male parent were identified as restorers, and if the $F_{1}$ test cross had sterile pollen, male parents were identified as maintainers. In the second experiment, we estimated heterosis in hybrid rice selected from the first experiment. The yield and yield components were collected from 4 middle plants of each hybrid, restorers, and check varieties. The following observation traits were collected: number of tillers, number of panicles, number of seeds per panicle, number of filled seeds per panicle, 1000 seed weight, plant height, flag leaf length, panicle length, harvest index, and yield at $15 \%$ moisture content for estimated heterobeltiosis, standard heterosis, and hybrid performances. The third experiment estimated the inheritance of fertility-restorer genes in rice including two $\mathrm{F}_{2}$ populations, with crosses between $\mathrm{CH} 1$ and $\mathrm{CH} 4$ (new plant type) as restorer lines and IR80151A (WA-CMS) as female parental line. The $F_{1}$ were left to produce $F_{2}$ seeds during the 2011 dry season. The $F_{2}$ populations were transplanted by using single seed per hill at $25 \mathrm{~cm}$ plant space, during the 2011 wet season. The $\mathrm{F}_{2}$ population size of crosses IR80151A/CH1 and IR80151A/CH4 were 414 and 448 plants, respectively. Both pollen and spikelet fertility data were collected. To study pollen fertility, anthers were collected from three randomly selected spikelets, pollen was stained with $2 \% \mathrm{IKI}_{2}$ solution, and the fertile and sterile pollen grain were counted in three fields of haemocytometer under microscope. The classification of pollen fertility and sterility groups was done according to Chaudhary et al ${ }^{16}$. Fertile plants gave more than $60 \%$ fertility pollen, 30-60\% pollen fertility was partial fertile, 1$30 \%$ fertility pollen was partial sterile and $0 \%$ fertility pollen was complete sterile. Seed setting rate (SSR), defined as the ratio between filled seeds per panicle to total seed per panicle, was recorded from 2 nonbagged panicles per plant. The classification of fertile and sterile groups as fertile plant was more than $2 \%$ SSR and less than $2 \%$ was sterile plants.

\section{RESULTS AND DISCUSSION}

The identification of rice germplasm was done by using test cross breeding. The 17 diverse genotypes were determined by test cross with 2 male sterile lines (IR80151A and CHA01). The germplasm, categorized on the basis of pollen and spikelet fertility, revealed 9 maintainers and 6 restorers which test cross progenies from CHA01 and 9 maintainers and 7 restorers from IR80151A (Table 1). The frequency of restorer and maintainer lines in this study was $58 \%$
Table 1 Classification of rice genotypes into restorers (R) and maintainers $(\mathrm{M})$ in a three lines hybrid rice system.

\begin{tabular}{lcc}
\hline Male parental lines & \multicolumn{2}{c}{ Female parental lines } \\
\cline { 2 - 3 } & CHA01 & IR80151A \\
\hline CH1 & $\mathrm{R}$ & $\mathrm{R}$ \\
CH2 & - & $\mathrm{R}$ \\
CH3 & $\mathrm{M}$ & $\mathrm{M}$ \\
CH4 & $\mathrm{M}$ & $\mathrm{R}$ \\
CT13432 & $\mathrm{R}$ & $\mathrm{M}$ \\
CNT1 & $\mathrm{M}$ & $\mathrm{R}$ \\
IR79156B & $\mathrm{M}$ & $\mathrm{M}$ \\
IR80151B & $\mathrm{M}$ & $\mathrm{M}$ \\
IR80156B & $\mathrm{M}$ & $\mathrm{M}$ \\
JHN & $\mathrm{R}$ & $\mathrm{M}$ \\
RD31 & - & $\mathrm{R}$ \\
SKN1 & $\mathrm{R}$ & $\mathrm{M}$ \\
SPR1 & $\mathrm{R}$ & $\mathrm{R}$ \\
SPR2 & $\mathrm{M}$ & $\mathrm{R}$ \\
SPR3 & $\mathrm{M}$ & $\mathrm{M}$ \\
SPR60 & $\mathrm{M}$ & $\mathrm{M}$ \\
SPR80 & & - \\
\hline
\end{tabular}

and $41 \%$, respectively. The germplasm used in this study include 9 Thai rice cultivars and 8 other rice germplasm. The 5 Thai maintainer lines could be used to develop adaptability of new male sterile lines for use in Thai hybrid rice research. Sarial and Singh ${ }^{6}$ identified 4 basmati maintainers and 4 basmati restorers based on pollen fertility and spikelet fertility. They were further categorized as effective restorers $(>80$ spikelet fertility), partial restorers $(21-79 \%$ spikelet fertility), and maintainers $(<1 \%$ spikelet fertility). Rosamma and Vijayakumar ${ }^{4}$ identified 4 restorers and 3 maintainers and Sabar and Akhter ${ }^{5}$ found 26 restorers and 34 maintainers selected based on pollen fertility and SSR. Several studies ${ }^{15,17,18}$, however have suggested that categorization on the basis of SSR is influenced by physiological and environmental conditions and could not be used to identify rice germplasm for three-line hybrid rice system. Hence the identification of maintainers and restorers of threeline hybrid rice system should be done based on pollen fertility of test cross hybrids.

The estimation of heterosis in hybrid rice is the greatest practical achievements for hybrid rice improvement ${ }^{7}$. In the second experiment, to estimate heterosis, 12 hybrids were crossed between 2 male sterile lines with 6 selected restorer lines from the first experiment. The result revealed that the two hybrids (HB7 and HB10) have high heterobeltiosis and standard heterosis (Table 2). The heterobeltioses are in the range of $-72 \%$ to $123 \%$ for HB6 and HB10, respectively. The hybrid yields of the highest and the lowest heterobeltiosis are 6790 and $1250 \mathrm{~kg} / \mathrm{ha}$, respectively (Table 3 ). However, the highest heterobeltiosis does not have the highest yield, so that the high heterobeltiosis could not be used to estimate the 
Table 2 Heterosis of $12 \mathrm{~F}_{1}$ hybrids in three lines hybrid rice system.

\begin{tabular}{llcc}
\hline HB & Crosses & $\begin{array}{c}\text { Hetero- } \\
\text { beltiosis }(\%)\end{array}$ & $\begin{array}{c}\text { Standard } \\
\text { heterosis }(\%)^{\dagger}\end{array}$ \\
\hline 1 & CHA01/CH1 & -28.9 & -35.8 \\
2 & CHA01/CNT1 & -0.6 & 8.5 \\
3 & CHA01/RD31 & -39.9 & -19.4 \\
4 & CHA01/CH4 & -46.6 & -70.7 \\
5 & CHA01/SPR1 & -26.8 & -20.1 \\
6 & CHA01/SPR2 & -71.7 & -77.5 \\
7 & IR80151A/CH1 & 57.7 & 42.5 \\
8 & IR80151A/CNT1 & -6.4 & 2.2 \\
9 & IR80151A/RD31 & -36.9 & -15.4 \\
10 & IR80151A/CH4 & 122.7 & 22.1 \\
11 & IR80151A/SPR1 & -90.9 & -90.0 \\
12 & IR80151A/SPR2 & 14.3 & -8.9 \\
\hline
\end{tabular}

average: $5560 \mathrm{~kg} / \mathrm{ha}$.

high yielding hybrid of this study. The estimation of standard heterosis was compared with average yield of check varieties $(5560 \mathrm{~kg} / \mathrm{ha})$, ranging between $-90 \%$ to $42 \%$ of HB11 and HB7, respectively. The yield of the highest standard heterosis is $7930 \mathrm{~kg} / \mathrm{ha}$, which means the standard heterosis is a truly heterosis of this study. However, the value of heterobeltiosis and standard heterosis depended on the data of their respective parents and check varieties. Tawari et al ${ }^{19}$ reported that more than $60 \%$ of standard heterosis compared with the best of check varieties has high specific combining ability of hybrid rice. Consequently, the best check varieties can be used to estimate the heterosis of hybrid rice.

The yield components of hybrids were estimated for number of tillers, number of panicles, number of seeds per panicle, number of filled seeds per panicle, 1000 seed weight, plant height, flag leaf length, panicle length, and harvest index. The data revealed that the average number of tillers ranges between 9.9 (HB4) and 41.4 tillers per plant (HB11). The number of panicles ranges between 9.6 (HB4) and 27.3 (HB2) panicle per plant. The average number of seeds per panicle, the most importance contributor to heterosis for high yielding hybrids ${ }^{20}$, ranges from 158.8 (HB9) to 323.3 (HB7). Seyoum et $\mathrm{al}^{21}$ reported that the number of filled seeds per panicle is associated with yield of rice. This study revealed a low SSR, with the average number of filled seeds ranging from 4 (HB6) to 217.9 (HB10) seeds per panicle. The two highest yield hybrids have high seeds per panicle, however, with low SSR $(61 \%$ and $77 \%$, respectively). The 1000 seeds weight ranges from 14.6 (HB4) to 23.7 (HB2). Rahima et al ${ }^{10}$ found that
1000 seeds weight is an important trait in developing high yielding hybrid. Plant height ranged between $81.9 \mathrm{~cm}$ (HB7) and $126.2 \mathrm{~cm}$ (HB7). Flag leaf length ranges between $31.9 \mathrm{~cm}$ (HB5) and $51.8 \mathrm{~cm}$ (HB1), which is associated with rice yield ${ }^{9}$. Panicle length ranged between $23.2 \mathrm{~cm}$ (HB5) and $27.6 \mathrm{~cm}$ (HB8) and harvest index ranges between 0.03 (HB11) and 0.51 (HB10). Babu et $\mathrm{al}^{22}$ reported that number of productive tillers per plant could bring improvement in the yield and yield components of hybrid rice.

The inheritance of fertility-restorer genes of two $F_{2}$ populations from $F_{1}$ fertile plants was examined by crossing male sterile and restorer lines (IR80151A/CH1 and IR80151A/CH4), where the IR80151A line was a WA-based cytoplasmic male sterility (WA-CMS) system in rice ${ }^{11}$. Tan et al ${ }^{12}$ reported that a monogenic trait controlled the fertilityrestorer gene of WA-CMS for some combinations, while other have reported digenic inheritance ${ }^{13,14}$, or digenic inheritance with epitasis ${ }^{15}$. Thus the identification of fertility-restorer genes is an important step in developing a three-line hybrid rice system. The inheritance of fertility restoration in both crosses based on pollen fertility revealed that $F_{2}$ segregates into 330 fertiles and 26 complete steriles for the cross IR80151A/CH1 and 385 fertiles and 29 complete steriles for the cross IR80151A/CH4, indicating that the expected 15:1 (fertile: sterile) ratio is good for both crosses (Table 4). The SSR (Table 5) shows an $\mathrm{F}_{2}$ segregation ratio of 15:1 for the cross IR80151A/CH4. The cross IR80151A/CH1 has significant segregation ration at 5\% statistic level, however the association of pollen fertility and SSR has a moderate value. The $R^{2}$ of both crosses (Fig. 1) are 0.58 and 0.62 for crosses IR80151A/CH1 and IR80151A/CH4, respectively. This suggests that the pollen fertility has an effect on SSR in the $F_{2}$ populations only $57 \%$ and $61 \%$ and has another effect among $43 \%$ and $39 \%$, respectively. The $\mathrm{F}_{2}$ segregated ratio of pollen fertility and $F_{1}$ fertility of both combination indicates that two dominant genes controlled the fertility restoration, in agreement with previous studies ${ }^{12-14}$. In this study, SSR could not be used to select male sterile plants and identify the inheritance of fertility-restorer genes in a WA-CMS system. In conclusion, the identification of rice germplasm plays a more important role in hybrid rice yield improvement. The local rice germplasm has a high frequency of maintainers than restorers. The estimated heterosis of new sources of germplasm could be selected to produce high yielding hybrid. Finally, the inheritance of fertility-restorer genes may have the high potentials for hybrid rice production and theoretical studies. 
Table 3 Yield and yield components of $12 \mathrm{~F}_{1}$ hybrids in three lines of hybrid rice system.

\begin{tabular}{|c|c|c|c|c|c|c|c|c|c|c|}
\hline \multirow[t]{2}{*}{ Crosses } & \multirow[t]{2}{*}{ tillers $^{\mathrm{a}}$} & \multirow[t]{2}{*}{ panicles $^{\mathrm{a}}$} & \multirow[t]{2}{*}{ seeds $^{\mathrm{b}}$} & \multirow[t]{2}{*}{ filled seeds ${ }^{b}$} & \multirow[t]{2}{*}{ weight $(\mathrm{g})^{\mathrm{c}}$} & \multicolumn{3}{|c|}{ height or length (cm) } & \multirow[t]{2}{*}{ harvest index } & \multirow[t]{2}{*}{ yield $^{\mathrm{d}}$} \\
\hline & & & & & & plant & flag leaf & panicle & & \\
\hline CHA01/CH1 & 14.4 & 11.0 & 270.0 & 120.1 & 19.4 & 102.0 & 51.8 & 5.9 & 0.48 & 3580 \\
\hline CHA01/CNT1 & 37.2 & 27.3 & 188.4 & 83.5 & 23.7 & 95.0 & 39.6 & 24.8 & 0.48 & 6040 \\
\hline CHA01/RD31 & 22.4 & 14.2 & 207.0 & 119.1 & 21.8 & 91.0 & 40.2 & 24.5 & 0.43 & 4480 \\
\hline CHA01/CH4 & 9.9 & 9.6 & 280.8 & 98.4 & 14.6 & 82.6 & 32.4 & 23.5 & 0.33 & 1630 \\
\hline CHA01/SPR1 & 24.1 & 15.1 & 227.0 & 109.7 & 22.3 & 88.3 & 31.9 & 23.2 & 0.47 & 4440 \\
\hline CHA01/SPR2 & 15.7 & 11.8 & 187.7 & 4.0 & 16.8 & 81.9 & 32.3 & 24.0 & 0.27 & 1250 \\
\hline IR80151A/CH1 & 19.4 & 15.7 & 323.3 & 198.8 & 17.8 & 126.2 & 50.9 & 27.2 & 0.46 & 7930 \\
\hline IR80151A/CNT1 & 17.9 & 14.8 & 187.2 & 108.5 & 21.9 & 123.9 & 46.4 & 27.6 & 0.50 & 5690 \\
\hline IR80151A/RD31 & 18.1 & 14.7 & 158.8 & 85.8 & 20.2 & 103.1 & 42.2 & 25.2 & 0.45 & 4710 \\
\hline IR80151A/CH4 & 14.4 & 14.6 & 284.3 & 217.9 & 18.5 & 109.6 & 46.3 & 25.0 & 0.51 & 6790 \\
\hline IR80151A/SPR1 & 41.4 & 17.1 & 179.0 & 18.9 & 20.6 & 115.9 & 43.3 & 23.9 & 0.03 & 560 \\
\hline IR80151A/SPR2 & 26.2 & 23.0 & 225.7 & 160.0 & 22.0 & 106.1 & 46.9 & 23.7 & 0.43 & 5060 \\
\hline $\mathrm{LSD}_{0.05}$ & 50.8 & 5.6 & 41.3 & 48.6 & 1.7 & 8.3 & 7.7 & 7.2 & 0.06 & 3040 \\
\hline
\end{tabular}

$\mathrm{LSD}_{0.05}$ : least significant difference at the 0.05 level.

a per plant, ${ }^{\mathrm{b}}$ per panicle, ${ }^{\mathrm{c}} 1000$ seeds, ${ }^{\mathrm{d}} \mathrm{kg} / \mathrm{ha}$.

Table 4 The segregation ratio of pollen fertility restoration in $\mathrm{F}_{2}$ populations of crosses IR80151A/CH1 and IR80151A/CH4.

\begin{tabular}{llccc}
\hline Traits & Pollen type & Observed & Expected & $\chi^{2}$ test $^{\dagger}$ \\
\hline CH1 & fertility & 330 & 353.4 & \\
& sterility & 26 & 23.6 & $1.81^{\text {ns }}$ \\
CH4 & fertility & 385 & 388.0 & \\
& sterility & 29 & 25.9 & $0.40^{\text {ns }}$ \\
\hline
\end{tabular}

critical $\chi^{2}$ for 1 degree of freedom is $3.84(p=0.05)$.

${ }^{\mathrm{ns}}$ Not significant at $5 \%$ statistical level.

Table 5 The segregation ratio of SSR in $\mathrm{F}_{2}$ populations of crosses between IR80151A/CH1 and IR80151A/CH4.

\begin{tabular}{llrrr}
\hline Traits & Spikelet type & Observed & Expected & $\chi^{2}$-test $^{\dagger}$ \\
\hline CH1 & $\geqslant 2 \%$ fertility & 344 & 353.4 & \\
& $<2 \%$ fertility & 33 & 23.6 & $4.03^{*}$ \\
CH4 & $\geqslant 2 \%$ fertility & 384 & 388.0 & \\
& $<2 \%$ fertility & 30 & 25.9 & $0.70^{\text {ns }}$ \\
\hline
\end{tabular}

${ }^{\dagger}$ critical $\chi^{2}$ for 1 degree of freedom is $3.84(p=0.05)$.

${ }^{\mathrm{ns}}$ Not significant at $5 \%$ statistical level.

* significant at 5\% statistical level.

\section{CONCLUSIONS}

The identification of restorers and maintainers of fertility is an important way to improve the hybrid vigour in rice. The results reveal 4 restorers and 4 maintainers of Thai rice cultivars and 2 restorers and 5 maintainers of exotic sources. The heterosis of hybrids shows a high heterobeltiosis and standard heterosis for HB7 and HB10. The classification of fertility-restoring
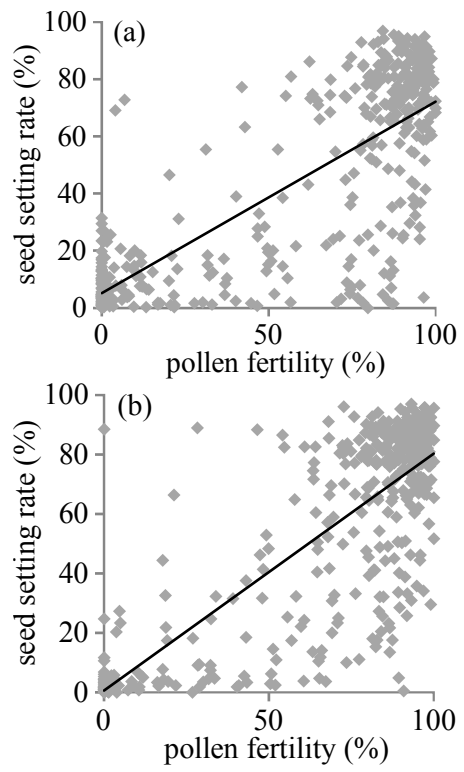

Fig. 1 Association between SSR and pollen fertility in $F_{2}$ populations of crosses (a) IR80151A/CH1 (line: $\left.y=0.669 x+5.2 ; R^{2}=0.58\right)$ and (b) IR80151A/CH4 (line: $y=0.797 x+0.6 ; R^{2}=0.62$ ).

genes and the segregated ratio of both $\mathrm{F}_{2}$ populations of 15:1 (fertile: sterile) indicate that IR80151A is WACMS, which is controlled by two dominant genes with sporophytic abortive. The SSR has been influenced by several physiological and environmental factors, so it could not be used to study the inheritance of fertilityrestorer genes. 
Acknowledgements: The authors gratefully acknowledge the Graduate School, Kasetsart University for providing a scholarship to conduct this study.

\section{REFERENCES}

1. Nair CKK (1993) Mitochondrial genome organization and cytoplasmic male sterility in plants. J Biosci 18, 407-22.

2. Ingale BV, Waghmode BD, Hodawadekar SS (2008) Identification of restorers and maintainers for different CMS lines of rice. Madras Agr J 95, 266-77.

3. Akther M, Zahid MA, Sabar M, Ahamd M (2008) Identification of restorers and maintainers for the development of rice hybrids. J Anim Plant Sci 18, 39-41.

4. Rosamma CA, Vijayakumar NK (2005) Maintainers and restorers for CMS lines of rice. J Trop Agr 43, 75-7.

5. Sabar M, Akhter M (2003) Evaluation of rice germplasm for the development of hybrid rice. Asian J Plant Sci 2, 1195-7.

6. Saria AK, Singh VP (2000) Identification of restorers and maintainers for developing basmati and nonbasmati hybrids in rice, Oryza sativa. Plant Breed 119, 243-7.

7. Parvez S (2006) Recent advances in understanding genetic basis of heterosis in rice (Oryza sativa L.). Rev Cient UDO Agr 6, 1-10.

8. Alam MF, Khan MR, Nuruzzaman M, Parvez S, Swaraz AM, Alam I, Ahsan N (2004) Genetic basis of heterosis and inbreeding depression in rice (Oryza sativa L.). J Zhejiang Univ Sci 5, 406-11.

9. Nuruzzaman M, Alam MF, Ahmed MG, Shohael AM, Biswas MK, Amin MR, Hossain MM (2002) Studies on parental variability and heterosis in rice. Pakistan $J$ Biol Sci 5, 1006-9.

10. Rahimi M, Rabiei B, Samizadeh H, Ghasemi AK (2010) Combining ability and heterosis in rice (Oryza sativa L.) cultivars. J Agr Sci Tech 12, 223-31.

11. Salgora RK, Gupta BB, Singh S (2009) Evaluation of various traits in some rice CMS lines that influence seed setting under subtropical conditions. Sabrao J Breed Genet 4, 115-22.

12. Tan YP, Li SQ, Wang L, Liu G, Hu J, Zhu YG (2008) Genetic analysis of fertility-restorer genes in rice. Biol Plantarum 52, 469-74.

13. Nematzadeh GA, Kiani G (2010) Genetic analysis of fertility restoration genes for WA type cytoplasmic male sterility in Iranian restorer rice line DN-33-18. Afr J Biotechnol 9, 6273-7.

14. Jing R, Li X, Yi P, Zhu Y (2001) Mapping fertilityrestoring genes of rice WA cytoplasmic male sterility using SSLP markers. Bot Bull Acad Sin 42, 167-71.

15. Hossian MS, Singh AK, Zaman F (2010) Genetic of fertility restoration of WA-based cytoplasmic male sterility system in rice (Oryza sativa) using indicaljaponica derivative restorers. Sci Asia 36, 94-9.
16. Chaudhary RC, Virmani SS, Khush GS (1981) Patterns of pollen abortion in some cytoplasmic male sterile lines of rice. Oryza 18, 140-2.

17. Akhter M, Zahid MA, Ahamd M, Haider Z (2008) Selection of restorers and maintainers from testcrosses for the development of rice hybrids. Pakistan J Sci 60 , $100-2$.

18. Malarvizhi D, Thiyagarajan K, Manonmani S, Sankar PD (2003) Fertility restoration behavior of promising CMS lines in rice (Oryza sativa L.). Indian J Agr Res 37, 259-63.

19. Tiwari DK, Pandey P, Giri SP, Dwivedi JL (2011) Heterosis studies for yield and its components in rice hybrids using CMS system. Asian J Plant Sci 10, $29-42$.

20. Zhou G, Chen Y, Yao W, Zhang C, Xie W, Hua J, Xing Y, Xiao J, Zhang Q (2012) Genetic composition of yield heterosis in an elited rice hybrid. Proc Natl Acad Sci USA 109, 15847-52.

21. Seyoum M, Alamerew S, Bantte K (2012) Genetic variability, heritability, correlation coefficient and path analysis for yield and yield related traits in upland rice (Oryza sativa L.). J Plant Sci 7, 13-22.

22. Babu VR, Shreya K, Dangi KS, Usharani G, Shankar S (2012) Correlation and path analysis studies in popular rice hybrids in India. Int J Sci Res Publ 2, 1-5. 